\title{
Research on the Protection Planning of Ancient City Wall
}

\author{
Wenyan Zhao ${ }^{\mathrm{a}}$, Liyue Pan \\ School of Mechanical Science and Engineering, Northeast Petroleum University, Heilongjiang, \\ Daqing, 163318 China \\ awydqpi@126.com, blyhb@foxmail.com
}

Keywords: ancient city; wall; protection

Abstract: The ancient city of China bears the historical accumulation of the nation and contains inestimable cultural value. The ancient city wall, as the bearer and participant of the ancient city, has experienced the reform and change of the city. Nowadays, the existence of the ancient city wall is contrary to the needs of urban development. Therefore, urban development needs to give full consideration to the particularity of the historical protection of the ancient city culture, and pay attention to the overall urban planning. With summarizing and analyzing the protection strategy of the building heritage protection at domestic and abroad, it is important to take effective measures to protect the cultural heritage of ancient city wall by the utilization of modern science and technology.

\section{Introduction}

As carriers and participants in the city, the wall is an important part of the ancient city. The protection of the ancient city wall is the protection of the ancient city and its cultural history. The ancient city wall reflects the regional and historical features at specific historical period in the material level. The ancient walls form building, plane form, road network structure, contour lines, partial axis relationships, sequence relationships, spatial scales and skylines in ancient city, etc [1]. At the same time, it contains the natural and artificial backgrounds related to the form of these materials, as well as the background of the historical environment in direct connection with space-time or the relation of social, economic and cultural ties. It includes the local people's lifestyle, customs and customs, and contains local characteristics and special features.

The ancient city walls are part of the heritage of historic and cultural cities. The protection of walls is also the protection of its history and culture. The purpose of protection is not only to save in simple sense, but to better cognize and use it. Appropriate heritage protection is based on the protection of modern functions of ancient city wall, and we insists on keeping balance between development, utilization and protection to used the wall reasonably and appropriately.

The function of the wall has changed in different historical periods. In modern times, the function of the wall has evolved from a unitary "utility-type" to a more diverse range of functions. As a cultural heritage, the ancient city wall continues to play a positive role to promote cultural and ideological progress in modern times. The transformation of wall function has a direct impact on the social functions of the ancient city walls and the protection and development of the government agency. The functional evolution of the research wall helps the academic community understand the 
evolutionary trajectory of social functions in different stages of the wall. Analyzing the effective ways and effects of the modern function of the wall will help promote academic research on the protection and development of the ancient city walls.

\section{The Ancient City Wall of China}

Traditional Chinese city wall has a variety of classifications. According to the traditional thoughts, the classification of the walls is summarized, and the main functions of different types of walls are analyzed, and their inherent cultural characteristics are revealed, which has positive significance for the protection planning of the ancient city wall. The classifications of wall include:

\subsection{Symbolic wall.}

As a typical symbolic wall, the archway used to eulogize the merits and express the etiquette in ancient times. The screen wall used to increase the unique temperament of the house, and it also has a practical function of blocking the sight in front of the gate.

\subsection{Defensive wall.}

As the largest defensive wall in China and the world, the Great Wall has played an important role in both spiritual and practical functions. The ramparts are often tens of feet high, which circling and protecting the city, and ramparts always built urn city in the gate of the city, which was used as a guarantee to import and export the city. Moreover, ancient imperial nobles, noble officials, and wealthy merchants built high walls to protect their homes [2].

\subsection{The Wall of Ancient Levels.}

In ancient times, people of different class status were different in their living and gathering places. They are separated by the demarcation line formed by palace walls, square walls, mansion walls, house walls, courtyard walls. If you are surrounded by "walls", you can distinguish the grade of the place of life through the external shape of the wall. In the process of using walls, the walls set city boundaries for the people in different ancient levels.

\subsection{Closed wall.}

In ancient time, Circumference of four walls is the symbol of closed wall. Wall surrounded by four sides means closed. The ancient city wall outside the ancient city, lv-li unit system of the ancient city is a closed layout. The walls of the enclosed layout also include the Imperial City Wall, the House Wall and the Courtyard Wall. The Lifang system greatly helped the management of the feudal rulers at that time. Nowadays, the walls of the Lifang system have historical remains but without material legacy.

Regardless of the walls of closed pattern, defensive function and ancient levels, they were used to meet the rule of the feudal ruler and to facilitate rhe management of the rulers of the edge of the border to the people.

\section{The Relationship and Contradiction between Urban Renewal and Ancient Wall Protection in City}

In the development and innovation of mordern city, the ancient city walls are covered every corner 
of the city, which conflicting with the modernization of the city and the effective use of the building's municipal resources. The mainly performances are:

- The contradiction from interests of cultural environment or other interests.

- The contradiction from economic interest of the residents. The protection of the ancient city is the protection of the cultural and historical features of the city, especially the walls of the ancient buildings and structures. As the most basic element in the city, it is closely related to the life of the residents. But the decline of function and the aging of materials can no longer satisfy the needs of the residents.

- The contradiction from economic interest of the developer. In the process of transformation of the ancient city, Real estate developers only look at near-term benefits during the transformation of old urban areas. Some unrelenting history and some irrevocable history and culture were mercilessly erased.

- The contradictions with unilateral "urban development concept" of the governments and the pursuit of short-term benefits. In addition, the development strategy of eagerness for quick success leads to hardly achievement of the subsequent protection and development planning.

- The contradiction from planning and development.

- The contradiction between massive investment in protection costs and shortage of funds ${ }^{[3]}$.

\section{The Protection, Inheritance, Development and Reuse of the Ancient City Walls}

The protection of the wall in the ancient city is more emphasis on groupness which is different from the condition of independent historic building or protection unit. The government plays an important role in protection and it also needs the peoples conscious awareness of protection at the same time. In addition, modern high-tech means can be used to count, store, digitally manage and protect the data of the ancient city walls before ancient buildings have irreversible damage, and perform digital management and protection. Moreover, as the carrier of life in the city, the protection should added some dynamic elements into the wall, and allowed the city to continuously develop its metabolism and increased its historical and cultural diversity. Take full advantage of itself within the maximum permitted scope of protection.

\subsection{Protection and control}

(1) It is necessary for the government to perform its functions to grasp the overall situation with strategic perspective and multiaspect. And government should protect history, abandon dirty and chaotic, strengthen infrastructure, and implement the planning of protection of ancient city into urban development.

(2) With the way of Strengthen legislative norms and make a reasonable assessment system, the ancient city wall is conducted with targeted protection and control.

(3) Modern science and technology should be used to scientifically manage and protect the old walls based on digital technology. . With the development of computer technology, some computer-based disciplines such as mapping, earth information systems, and three-dimensional laser scanner technique have been well developed in protecting the walls. Three-dimensional laser scanning technology is used to data processing of architectural heritage, and three dimensional stereoscopic model is constructed. Three-dimensional reconstruction is an important means for the protection of architectural heritage [4]. GIS (Geographic Information System) technology integrates data in many aspects, strengthens data management, visualizations and management of data. By simulating some data, it can prevent and deal with the hazards that the building may encounter, and provide auxiliary help for the protection of the building heritage [5]. 
(4) The propaganda of the people's awareness of protection should be strengthened to win the support of conscious protection of architectural heritage from the people.

(5) Protection of international cooperation should be applied, such as the application of world cultural heritage.

\subsection{Development and utilization}

The traditional way of protection is to build heritage conservation units, such as museums. But the preservation of "encase" will get architectural heritage forgotten soon. The optimized protection is to inject the walls into new vitality elements instead of simple preservation, and carry out normal metabolism so as to better protect the architectural heritage. By adding social elements and urban functions into the walls, architectural heritage enables to continue "survive".

In the development and utilization of walls, we should develop the way of point, line and plane. The point is that some key protected walls are used as the main protection object and the use of the surrounding landscape resources are integrated. The line is used to sort out the landscape points of these key walls. And through the arrangement of public service facilities, these attractions are linked together. Surface, that is, the overall planning of these different grades, different types, different lines of the wall sets into a net. This kind of development and utilization forms the ancient city as an organic whole and allows the city to have its own characteristics and create city business cards.

\section{Foreign case}

Hakodate Bay, Hokkaido, Japan was converted into Fashion Business District Case. Japanese architect Okada Shinichi transformed a brewery in Sapporo. The building uses red bricks as the main building material and is a relatively rare brick architectural heritage in Japan. Okada carried out a reconstruction plan for the brick architectural heritage. He transformed the factory into a variety of commercial facilities, making full use of the indoor mottled red brick walls and special lighting design to create a unique aesthetic. In 1988, Okada Shinichi converted some warehouses located in Hakodate Bay, Hokkaido, into fashion complexes. While maintaining the original building, some renovations were made in some places. The roof was replaced by a metal roof and the original walls were not touched. The texture of the roof and walls contrasts sharply. It blends into the surrounding environment with a new image. Other newly constructed places use high gloss glass and black steel. The warehouses on both sides are connected by a flyover on the canal. Okadashin's warehouse renovation in the area is not only the protection of cultural assets, but also restores the function of the area and rejuvenates it [6].

\section{Conclusion}

The ancient city of China is not only an area where the overall structure and style of the heritage are concentrated, but also a complex of the material cultural heritage and the intangible cultural heritage. It is also the main carrier of economic and social development. Through in-depth study of the walls in the ancient city, around the content of the ancient city to determine the contents of protection, with space as a carrier, while strengthening the overall protection of the ancient city pattern and style, it is also necessary to closely integrate the intangible cultural heritage and the material cultural heritage. Together, it highlights the integrity of the protection theme and the ancient city of history and culture. Integrate these historical and cultural resources scattered in the city, pay attention to the spatial layout of the current situation on the ground, and promote the harmonious development of the urban economy and society. 


\section{References}

[1] Yu Liu. Research on the protection of historic and cultural cities and urban renewal [D]. Tianjin University, 2006.

[2] Xiangdong Zhu, Zhaotao Cheng. Chinese traditional construction ideas and "wall" culture [J]. Shanxi Architecture, 2005 (08): 1-2.

[3] Chao Yin. Research on the Spatial Pattern Protection of Nanjing Ancient City [D]. Southeast University, 2005.

[4] Wenbo Peng, Wuian Yang, Peng Wang. Application of 3D Laser Scanning Technology in Reconstruction of Ancient Architectural Models [J]. Geospatial Information, 2016, 14(03): 94-96+9.

[5] Zhangwei FAN, Hao XING. Research on protection of ancient architecture based on digital technology [J]. Beijing Surveying and Mapping, 2010(03):18-21+35.

[6] Li Jiang. Case 2 Example of protection of historic buildings abroad [A]. Capital University of Economics and Trade, Beijing Municipal Social Science Association. 2011 Urban Internationalization Forum-Metropolitan Governance in the Process of Globalization (Case Set) [C]. Capital University of Economics and Trade, Beijing Municipal Federation of Social Sciences: 2011: 2. 